\title{
Primary Hyperparathyroidism in Children, Adolescents, and Young Adults
}

\author{
Maria Allo, M.D., Norman W. Thompson, M.D., Jay K. Harness, M.D., and Ronald H. Nishiyama, M.D. \\ Departments of Surgery and Pathology, University of Michigan Medical Center, Ann Arbor, Michigan, U.S.A.
}

Primary hyperparathyroidism (HPT) is considered a rare disease in children and an uncommon one in adolescents and young adults. Until 1975 , only 60 children under the age of 16 years had been reported with proven HPT. Most had symptoms of weakness, irritability, anorexia, and weight loss. Severe hypercalcemia (serum calcium $>15 \mathrm{mg} /$ $100 \mathrm{ml}$ ) and radiologic evidence of bone changes were common findings, and suggested delayed diagnoses.

This report is based on the clinical and laboratory findings in 53 young patients with proven primary HPT (range: 1-30 years of age) from 1971 to 1980, treated in one hospital. There were 29 male and 24 female patients, 26 of whom developed symptoms before age 18 . Common symptoms included hematuria and renal colic $(50 \%)$, renal calculi $(50 \%)$, and hypertension with $(6 \%)$ and without (3\%) severe headaches. Although $64.2 \%$ of patients had adenomas, only $54 \%$ of patients under 18 , and as many as $77.8 \%$ over 18 , had them. The incidence of hyperplasia was markedly increased in the patients under $18(38 \%)$ as compared to the patients over $18(18.5 \%)$ or the group taken as a whole $(30.2 \%)$. The following associated diseases were identified: MEA I syndrome (4); MEA II syndrome (4); von Recklinghausen's neurofibromatosis; papillary carcinoma of thyroid; craniopharyngioma; and multiple metaphyseal chondromatosis. One child had hereditary neonatal parathyroid hyperplasia.

Primary hyperparathyroidism is more common than previously suspected in young people. Symptoms of renal stones, hypertension, persistent headaches, unexplained anorexia, and weight loss should prompt evaluation for primary HPT. If hyperplasia is found, the patient and family should be investigated for associated endocrinopathies.

Presented before the annual meeting of the International Association of Endocrine Surgeons, Montreux, Switzerland, September, 1981.

Reprint requests: Maria Allo, M.D., Department of Surgery, Denver General Hospital, West 8th Avenue \& Cherokee Street, Denver, Colorado 80204, U.S.A.
Primary hyperparathyroidism (HPT) has only rarely been reported in children and is unusual in teenagers and young adults. The first case was reported in 1930 by Pemberton and Geddie [1] in a 14-yearold boy with hypercalcemia, hypercalciuria, osteoporosis, and complaints of polyuria, constipation, and vomiting. Until 1970, only 43 documented cases had been reported [2]. Three additional patients were reported by Mannix in 1975 [3]. In 1977 the largest series from a single institution contained only 10 children [4]. From these reports differences between adults and children emerged with respect to sex distribution, histopathology, and clinical presentation.

Since 1971,53 cases of primary hyperparathyroidism were seen at University of Michigan Medical Center in persons under 30 years of age. A third of these patients were less than 18 years old. This is the largest series of young patients from a single institution cared for by a single surgeon (NWT). Although many of our conclusions corroborate the observations made in earlier reports, the size of this cohort has provided a unique data base on which to confirm these earlier observations as well as to make new observations.

\section{Methods}

From 1971 to 1980 , a total of 53 patients aged $0-30$ years underwent neck exploration for primary HPT. In all cases, attempts were made to identify 4 parathyroid glands, and frozen section confirmation was obtained to verify the presence of parathyroid tissue. When an adenoma and at least 1 histologically normal gland were identified, a diagnosis of adenoma was made. Excision of the adenoma and biopsy of the remaining gland was felt to be adequate treatment. When multiple glands were found to be hyperplastic, $3 \frac{1}{2}$ - or $3 \frac{3}{4}$-gland excision was 
done. Exceptions were infants with neonatal hyperparathyroidism who underwent total parathyroidectomy (1 patient) and patients with MEA II in whom only the enlarged gland or glands were removed rather than $3 \frac{1 / 2}{2}$ or $3 \frac{3}{4}$ glands. In patients in whom 4 glands were not found, neck exploration included examination of the thyrothymic tract, the "parathymic" zone from the upper border of the larynx into the anterior mediastinum, the area adjacent to the carotid space, and the cricoesophageal space. Preoperative localization studies including selective venous samplings were obtained only in patients who had recurrent disease following initial neck exploration. One patient who had had 4 normal glands on initial exploration had persistent hypercalcemia postoperatively. She underwent arteriography which localized a mediastinal adenoma that was subsequently treated successfully by embolization.

Careful histopathologic review of all specimens removed at the time of operation was carried out.

All patients were followed at least annually. One patient who was followed for the first 4 years after operation was subsequently lost to follow-up.

\section{Results}

\section{Clinical Data}

Of 53 patients in our series, 30 were male and 23 were female, the sex ratio for the entire group being 1.4 males: 1 female. Nearly one-third of the patients (17/53) had symptoms before age 18 years, and in this group female patients outnumbered males (1.4:1). Among patients over age 18 , the sex ratio was 2 males: 1 female. Table 1 shows the age distribution of the patients at the time of operation and at onset of symptoms. Most patients had symptoms for an average of 2 years prior to operation (mean, 2.3 years; range, 0-11 years). Seventeen gave no antecedent history of any clinical manifestation of parathyroid disease.

Although 51 of the patients were hypercalcemic (normal, $8.8-10.4 \mathrm{mg} / 100 \mathrm{ml}$ ), most sought medical attention for other reasons. The most frequent presenting symptom was that of renal colic [ 27 of 53 patients $(51 \%)$ ]. Nine patients were severely hypertensive. All the hypertensive patients were hypercalcemic, and two-thirds of them had headache as their primary symptom. Bone changes occurred in only 3 patients $(6 \%)$. One-third of the patients had non-specific complaints of weakness, fatigue, and malaise. In about half of the patients with nonspecific symptoms, there was objective weight loss. Five patients were asymptomatic at the time of diagnosis: 3 had hypercalcemia on family screening
Table 1. Age of onset of symptoms and at operation.

\begin{tabular}{cccc}
\hline $\begin{array}{l}\text { Onset } \\
\text { (years) }\end{array}$ & $\begin{array}{l}\text { No. of } \\
\text { patients }\end{array}$ & $\begin{array}{l}\text { Operation } \\
\text { (years) }\end{array}$ & $\begin{array}{l}\text { No. of } \\
\text { patients }\end{array}$ \\
\hline $0-10$ & 3 & $0-10$ & 3 \\
$11-14$ & 10 & $11-14$ & 5 \\
$15-18$ & 12 & $15-18$ & 9 \\
$19-25$ & 21 & $19-25$ & 19 \\
$26-30$ & 7 & $26-30$ & 17 \\
Total & 53 & & 53 \\
\hline
\end{tabular}

Table 2. Presenting complaints and physical findings in 53 young patients with primary hyperparathyroidism (19711980).

\begin{tabular}{lc}
\hline Complaints or finding & \% of patients \\
\hline Renal stones & 50 \\
Hypertension & 17 \\
Malaise, fatigue, weakness & 30 \\
Bony abnormalities & 6 \\
Asymptomatic & 10 \\
\hline
\end{tabular}

for MEA II, and had enlarged parathyroids at the time of total thyroidectomy for medullary carcinoma of the thyroid; 1 had an elevated calcium on routine SMA screening battery; and 1 was incidentally found to be hypercalcemic during evaluation for a brain tumor. These data are summarized in Table 2.

Several associated diseases were found. These associated conditions in young patients with primary HPT are listed in Table 3.

\section{Type of Treatment}

Thirty-five patients had adenomas. All of these patients had their tumors excised and the remaining glands biopsied. Two patients had 4 normal parathyroid glands identified at operation and this was confirmed by histological examination. One of these patients subsequently underwent angiography which identified a mediastinal adenoma that was embolized. The second patient remains hypercalcemic (mean serum calcium level, $11.4 \mathrm{mg} / 100 \mathrm{ml}$ ).

Three and one-half-gland excision was performed in 14 patients with hyperplasia. Three other patients with hyperplasia were members of MEA II families and were treated with excision of only the hyperplastic glands. One neonate who presented in hypercalcemic crisis underwent total parathyroidectomy.

Hypocalcemia was the most frequently observed complication in this series. Six patients became hypocalcemic postoperatively. All but 1 of these patients had undergone $3 \frac{1}{2}$ - or $3 \frac{3}{4}$-gland excision 
Table 3. Diseases associated with HPT in young people.

\begin{tabular}{ll}
\hline Disease & $\begin{array}{l}\text { No. of } \\
\text { patients }\end{array}$ \\
\hline MEA I syndrome & 6 \\
MEA II syndrome & 4 \\
Neurofibromatosis & 1 \\
Papillary carcinoma of thyroid & 1 \\
Craniopharyngioma & 1 \\
Metaphyseal chondromatosis & 1 \\
Fibrous dysplasia of the jaw & 1 \\
Familial solitary adenoma [12] & 2 \\
Kallmann's syndrome & 1 \\
\hline
\end{tabular}

Table 4. Histopathology in 53 cases of primary hyperparathyroidism in young persons.

\begin{tabular}{llll}
\hline & $\begin{array}{l}\text { Under } \\
18 \text { years }\end{array}$ & $\begin{array}{l}\text { Over } \\
18 \text { years }\end{array}$ & Total \\
\hline Adenoma & 8 & 27 & $35(67 \%)$ \\
Hyperplasia & 9 & 8 & $17(33 \%)$ \\
Normal glands & 1 & 0 & 1 \\
\hline
\end{tabular}

for hyperplasia. The remaining patient had had a histopathologic diagnosis of hyperplasia made on frozen sections of several slightly enlarged glands and underwent 33/4-gland excision. In retrospect, permanent sections of all but 1 gland showed normal histology, and he probably had a solitary adenoma.

One patient had persistent hypercalcemia despite identification and biopsy of 4 normal-sized parathyroids at operation. Localization studies are planned to look for a fifth gland.

No patient had complications of bleeding, recurrent laryngeal nerve injury, or infection. There were no deaths.

\section{Surgical Pathology}

Among the entire group, two-thirds of the patients had parathyroid adenomas and the remainder chief cell hyperplasia (Table 4). Hyperplasia was more common in patients under 18 years of age. Thus, among patients under 18 years of age, 8 patients $(47 \%)$ had adenomas and $9(53 \%)$ had hyperplasia. One other patient mentioned previously probably has an adenoma in a 5 th gland. Among patients over 18 years of age, 27 patients $(77 \%)$ had adenomas and 8 patients $(23 \%)$ had hyperplasia. The sex and age distribution of histopathologic lesions is summarized in Table 5. Twice as many males over 18 had adenomas as females, precisely the opposite of what one would expect in the total adult population where the markedly increased incidence of primary
Table 5. Sex and age distribution by histopathologic lesion.

\begin{tabular}{lllllll} 
& \multicolumn{2}{c}{ Males } & & \multicolumn{2}{l}{ Females } \\
\cline { 2 - 3 } \cline { 5 - 6 } & Under 18 & Over 18 & Under 18 & Over 18 \\
\hline Adenoma & 2 & 18 & $6^{a}$ & 9 \\
Hyperplasia & 5 & 5 & 4 & 3
\end{tabular}

aAll patients had passed menarche.

hyperparathyroidism in post-menopausal women results in twice the frequency of this disease in women as compared to men [1]. The incidence of hyperplasia was equal among males and females of all ages, attesting to the autosomal dominant transmission in most familial forms of hyperparathyroidism.

\section{Follow-up}

The majority of patients have been followed for more than 2 years after operation. Fifty-one of the patients are normocalcemic and have required no further treatment. One patient has persistent hypercalcemia. Studies to identify a mediastinal adenoma are planned. Another patient who became hypocalcemic following operation requires calcium replacement to remain normocalcemic. None of the other 5 patients who had become hypocalcemic postoperatively currently require treatment. All are normocalcemic. Of 9 hypertensive patients, 8 have been documented to be normotensive. The ninth patient, though known to be normocalcemic 3 years after parathyroidectomy, was subsequently lost to follow-up. Only 1 of the patients who presented with renal colic passed stones postoperatively. Preoperatively, however, she had had many stones in the renal pelvis.

\section{Discussion}

Previous reviews [2-5] of primary HPT in children note an increased incidence of hyperplasia, as compared to an adult population, and a greater incidence in males. Despite the fact that 2 earlier reviews $[2,4]$ downplayed the importance of renal colic as a presenting symptom, this was the single most common presentation in our series. The majority of our patients with adenomas were young men with renal calculi. It was notable that the incidence of adenomas in patients aged 19-30 years was approximately that reported for adult popula- 
tions $(77 \%)$ but that the sex ratio was exactly reversed ( 2 males: 1 female). No adenomas were seen in prepubertal girls, and only 2 boys under age 16 had adenomas. One of them was a 14-year-old with Kallmann's syndrome [6]. A relationship between sex hormone levels or production and development of parathyroid adenoma has not been defined.

Similarly, although hypertension [5] has been reported in association with primary HPT in children, this report did not indicate this on follow-up. Eight patients in the present series have been normotensive following parathyroidectomy (average follow-up, 3.5 years).

The predominance of vague presenting symptoms of fatigue, weakness, irritability, and malaise was borne out in this series. There was no apparent correlation between the PTH or calcium levels and either the duration of symptoms or clinical presentation, with the obvious exception of a neonate who presented in a hypercalcemic crisis. One needs to have a high index of suspicion if the diagnosis is to be made, and children with symptoms of weakness, fatigue, malaise, unexplained hypertension, headaches, weight loss, or constipation should be screened for hypercalcemia and possible HPT if other causes of these symptoms are not evident.

In a third of the total cases the pathologic lesion was chief cell hyperplasia, but in the group of patients under 18, half of the patients had this lesion. Further, there was no sex predilection in either the younger patients with hyperplasia or in the total group. Ten of the 17 patients with hyperplasia belonged to families with documented multiple endocrine adenomatosis syndromes. The 6 patients from MEA I families all presented with symptoms of lethargy and weakness, and 1 had nephrolithiasis. In contrast, 3 of the 4 patients with MEA II had no symptoms. One of them had significant elevation of serum calcium on a screening panel and serum PTH level was also increased; the others were normocalcemic but were found to have asymmetrically enlarged parathyroids at the time of total thyroidectomy for medullary carcinoma of thyroid. Histopathology showed chief cell hyperplasia. The approach to patients with MEA II differs from that employed in patients with hyperplasia due to other causes. Only the enlarged gland(s) are removed. This is done even in patients who are asymptomatic at the time of thyroidectomy for medullary carcinoma of the thyroid because clinical HPT with hypercalcemia often develops later in these patients. At the University of Michigan there have been no recurrences of HPT following removal of only the enlarged glands in patients with MEA II (unpublished data, NWT). Furthermore, 31/2-gland excision in patients with MEA II leads to a very high incidence of permanent hypocalcemia. While it is unusual for patients with MEA II to present with hyperparathyroidism, 1 of the 4 patients in this series did. She had renal colic, hypercalcemia, and PTH elevation.

Although pancreatitis [7] and peptic ulcer disease $[3,8]$ have been associated with hyperparathyroidism, none of these patients had those diseases.

No patients in this series had parathyroid carcinoma. A series of 70 cases of parathyroid carcinoma reported by Schantz and Castleman [9] included $16 \%$ of cases in patients under 30 , the youngest of whom was 13 . Recently, one case of parathyroid carcinoma has been reported in a child [10], and this was not associated with familial disease. Dinnen et al. [11] have reported 2 families, however, with parathyroid carcinoma documented in patients early in the fourth decade.

This series suggests that primary hyperparathyroidism is more common than previously recognized in children and young adults. The symptoms may be subtle, and the diagnosis missed unless the clinician has a high index of suspicion. Young patients with renal stones, headaches, and hypertension should be evaluated for hypercalcemia. If hypercalcemic, further evaluation for hyperparathyroidism should be undertaken. Young patients whose anorexia, irritability, weight loss, fatigue, malaise, or constipation cannot be ascribed to some other cause should also be screened. Because of the relatively greater frequency of hyperplasia in children, and its association with familial parathyroid disease, a careful family history should be taken. In young patients with parathyroid hyperplasia, evaluation for other endocrinopathies should be performed and other family members should also be investigated.

\section{Résumé}

L'hyperparathyroïdie est considérée une maladie extraordinaire des infants et bien rare des adolescents et des jeunes adultes. Jusqu'à 1975, seulement 60 enfants qui avaient moins de 16 ans étaient rapportés avec l'hyperparathyroïdie verifiée. La majorité avaient les symptômes de faiblesse, irritabilité, anorexie et perdu des poids. L'hypercalcémie severe (calcémies $>15 \mathrm{mg} / 100 \mathrm{ml}$ ) et l'évidence radiologique d'abnormalitiés osseux sont les conclusions ordinaires, et cela donne l'idée que le diagnostic était tard.

Ce rapport présente les données cliniques et du laboratoire de 53 malades jeunes avec l'hyperparathyroïdie verifiée (1-30 ans) pendant dix ans entre 
1971 à 1980 qui ont recu les traitements dans le même hôpital.

Vingt-neuf étaient mâle; 24 étaient female. Vingtsix ont developés les symptômes avant qui avaient 18 ans. Les symptômes assez répandue englobait hematurie avec la colique des reins $(50 \%)$, des calculs rénals $(50 \%)$, et hypertension artérielle avec (6) et sans (3) mal à tête sévère.

$64.2 \%$ des malades avaient l'adenômes compris seulement $54 \%$ des malades qui avaient moins de 18 ans et jusqu'à $77.8 \%$ qui avaient 18 ans et davantage. L'incidence d'hyperplasie était augmentée des malades qui avaient moins de 18 ans $(38 \%)$ en comparaison de ceux qui avaient 18 ans et davantage $(18.5 \%)$ ou toutes les malades $(30.2 \%)$. L'hyperparathyroïdie était associée avec: MEA I (4); MEA II (4); neurofibromatose de von Recklinghausen; carcinomie papillaire de thyróidie; craniopharyngioma et "multiple metaphyseal chondramotosis." Un enfant avait hyperplasie neonatal, héréditaire de parathyroïdie.

L'hyperparathyroïdie des jeunes malades est plus ordinaire qu'on pense bien auparavant. Les symptômes de calculs rénals, hypertension artérielle, mals à tête persistants, anorexie inexpliqué et perdu des poids demandent l'evaluation prompt d'hyperparathyroïdie. Si l'hyperplasie de parathyroïdie est trouvée, on doit étudier le malade et sa famille pour chercher des autres endocrinopathies associées.

\section{Invited Commentary}

\author{
Henry Mannix, Jr., M.D. \\ Hartford, Connecticut, U.S.A.
}

Primary hyperparathyroidism in children under 16 years of age is a rare condition. I could collect only 60 cases when reporting my experience in 1975. By January of 1982, Girard and associates [1] from Montreal reviewed the subject and were able to find 86 documented cases of hyperparathyroidism in childhood in the world literature. They broke down the material thusly: 17 patients had disease in the neonatal period; all had parathyroid hyperplasia; one 12-year-old had familial hyperparathyroidism with no other endocrine disturbance; 68 patients had no known genetic condition. Adenoma was found in 54 instances, hyperplasia in 3 patients, and the pathological findings were not described in 11 patients. Girard emphasized the importance of aggressive surgery in the neonate. In this review, there was no mention of associated endocrinopathies.

\section{References}

1. Muller, H.: Sex, age and hyperparathyroidism. Lancet $l: 449,1969$

2. Pemberton, J. de J., Geddie, K.G.: Hyperparathyroidism. Ann. Surg. 92:202, 1930

3. Bjernulf, A., Hall, K., Sjogen, J., Werner, I.: Primary hyperparathyroidism in children. Acta Pediatr. Scand. 59:249, 1970

4. Mannix, H., Jr.: Primary hyperparathyroidism in children. Am. J. Surg. 129:528, 1975

5. Shcherbacheva, L.N.: Hyperparathyroidism in children. Pediatriia 9:77, 1972

6. Bardin, C.W., Paulsen, C.A.: The testes. In Textbook of Endocrinology, R.H. Williams, editor, Philadelphia, W.B. Saunders, 1981, p. 328

7. Daum, F., Rosen, J.F., Boley, S.T.: Parathyroid adenoma, parathyroid crisis and acute pancreatitis in an adolescent. J. Pediatr. 83:275, 1973

8. Sandler, L.M., Moncrieff, M.W.: Familial hyperparathyroidism. Arch. Dis. Child. 55:146, 1980

9. Schantz, A., Castleman, B.: Parathyroid carcinoma. Cancer 31:600, 1973

10. Fujimoto, Y., Kanazawa, K., Aiyoshi, Y., Obara, T., Ito, Y., Esaki, M.: Carcinoma of the parathyroid gland. World J. Surg. 5:462, 1981

11. Dinnen, J.S., Greenwood, R.H., Jones, J.H., Walker, D.A., Williams, E.D.: Parathyroid carcinoma in familial hyperparathyroidism. J. Clin. Pathol. 30:966, 1977

12. Allo, M.D., Thompson, N.W.: Familial hyperparathyroidism due to solitary adenomas. Surgery (In press)

In the present study from Michigan, the authors report the largest series of patients under 18 in the literature. One of the striking points in Allo's article is the incidence of associated endocrinopathy. Eighteen patients apparently had associated problems that could be genetic in origin. It is of interest that only 1 infant with hereditary neonatal hyperplasia was reported in contrast to the Girard review. However, a strikingly high percentage $(30 \%)$ of the younger patients had hyperplasia as the cause of the disease.

In two-thirds of the patients over 18 years of age, their symptomatology was similar to that seen in the usual group of patients. The only exception was a low incidence of bone disease. In addition, in this group adenoma was the predominant cause of disease. The major symptoms in both groups were renal and vague non-specific symptoms previously reported.

To me, the most striking feature of this report is the extremely high incidence of asociated conditions. Ten of the patients had either MEA I or MEA II syndrome. Certainly, this makes one wonder if there are not several families in the Ann Arbor area with these problems. In Hartford, Connecticut, 